\title{
Assessing emergency obstetric and newborn care: can performance indicators capture health system weaknesses?
}

\author{
Andrea Solnes Miltenburg ${ }^{1,2^{*}}$, Richard Forget Kiritta ${ }^{3}$, Thabea Benedicto Bishanga ${ }^{4}$, Jos van Roosmalen ${ }^{5,6}$ \\ and Jelle Stekelenburg 7,8
}

\begin{abstract}
Background: Regular monitoring and assessment of performance indicators for emergency obstetric and newborn care can help to identify priorities to improve health services for women and newborns. The aim of this study was to perform a district wide assessment of emergency obstetric and newborn care performance and identify ways for improvement.

Methods: Facility assessment of 13 dispensaries, four health centers and one district hospital in a rural district in Tanzania was performed in two data collection periods in 2014. Assessment included a facility walk-through to observe facility infrastructure and interviews with facility in-charges to assess available services, staff and supplies. In addition facility statistics were collected for the year 2013. Results were discussed with district representatives.

Results: Approximately $65 \%$ of expected births took place in health facilities and $22 \%$ of women with complications were treated in facilities expected to provide emergency care. None of the facilities was, however, able to perform at the expected level for emergency obstetric and newborn care since not all required signal functions could be provided. Inadequate availability of essential drugs such as uterotonics, antibiotics and anticonvulsants as well as lack of ability to perform vacuum extraction and blood transfusion limited performance.

Conclusions: Performance of emergency obstetric and newborn care in Magu District was not in accordance with expected guidelines and highly influenced by lack of available resources and an insufficiently functioning health care system. Improving assessment approaches, to look beyond the signal functions, can capture weaknesses in the system and will help to understand poor performance and identify locally applicable ways for improvement.
\end{abstract}

Keywords: Emergency obstetric and newborn care, Signal functions, Resource problems

\section{Background}

Emergency Obstetric and Newborn Care (EmONC) must be available and accessible to all women in order to avert maternal deaths and morbidities from the most frequent causes as haemorrhage, sepsis, eclampsia, obstructed labour and abortion complications. EmONC can also prevent fresh stillbirths and early neonatal deaths and morbidities [1].

\footnotetext{
* Correspondence: a.solnesmiltenburg@gmail.com

'Institute of Health and Society, Department of Community Medicine and Global Health, Faculty of Medicine, University of Oslo, Oslo, Norway

${ }^{2}$ Women Centered Care Project, a project of the African Woman Foundation,

Magu, Mwanza Region, Tanzania

Full list of author information is available at the end of the article
}

The past decades Tanzania has given Reproductive Maternal Neonatal and Child Health (RMNCH) high priority which at policy level resulted in development of the 'One Plan - to accelerate reduction of maternal, newborn and child deaths between 2008 and 2015' [2, 3]. Implementation of policies, primarily the responsibility of regional and district councils, has received less attention, especially with regards to specific maternal and neonatal interventions $[2,4]$. As a consequence insufficient progress has been made to reduce maternal and neonatal mortality, in particular in the Western and Lake Zone regions $[2,3]$.

There is no single intervention that works to achieve the desired reduction in maternal and neonatal mortality [5], as direct and underlying causes for poor maternal 
health and mortality are complex [6]. Along the continuum of care from pre-conception to post-birth as well as from individual-, family-, community level up to facility and policy level, packages of interventions can have great impact if implemented well [7]. Skilled care at birth and access to EmONC is of vital importance especially for those $15 \%$ of pregnant women who are expected to experience life-threatening maternal and/or neonatal complications [8].

Over the years useful process indicators have been developed to evaluate availability, accessibility and quality of EmONC [9, 10]. Regular assessment and monitoring of EmONC indicators can help programme planners in the field of RMNCH to identify priorities and needs to strengthen health services for women and their newborns [10]. The aim of this study was to perform a district-wide assessment of EmONC performance, to identify gaps and propose ways for improvement.

\section{Methods \\ Setting}

Magu District is one of eight districts of Mwanza Region of Tanzania and is bordered to the north by Lake Victoria and to the west by the city of Mwanza, which is the second largest city in Tanzania. The estimated population in 2012 was 299,759 [11]. Magu district had 46 health facilities: one government district hospital, four government health centres, 30 government dispensaries, nine private dispensaries, one faith based dispensary and one parastatal dispensary. Out of all government health facilities 31 provided antenatal, delivery and postnatal care. In terms of ownership, facilities are funded and supported by the district council of which the Council Health Management Team (CHMT) is responsible for decision-making. Main actors in the provision of maternal health care are (assistant) medical officers, clinical officers, enrolled and registered nurses/midwives, as well as medical attendants.

Since 2012 the Woman Centered Care Project (WCCP), a project of the African Woman Foundation [12-14], has been performing baseline research activities in the district and formed a partnership with the Magu District Council with the aim to improve accessibility and availability of quality maternal health care. Although focus has mainly been on antenatal care services and community involvement, the project together with members of the CHMT discussed the need for an EmONC assessment as improvements in the health situation of women in the district can only be reached when the complete system functions well along the continuum of care.

\section{Data collection}

This study is based on two periods of data collection. A facility survey was performed at 13 dispensaries, one health centre and the district hospital in April-May 2014, including investigation of the availability of supplies and medicines to provide basic EmONC. Facilities were selected purposefully based on participation in the WCCP project locations. In December 2014 an EmONC assessment was performed including assessments at the district hospital and all four health centres in the district regarding their EmONC performance within the past three months. The research team interviewed (assistant) clinical officers or nurses in charge of the facilities. Facility visits included a walk-through to observe facility infrastructure, available services, staff and supplies. Maternal death review forms of 2013 were also reviewed. During the field visits and during meetings with different members of the CHMT and other stakeholders relevant observations were documented and discussed.

\section{Data collection tools}

For the facility survey in April-May a tool was developed based on the Johns Hopkins Program for International Education in Gynecology and Obstetrics (JHPIEGO) manual for monitoring birth preparedness and complication readiness [15]. The tool was digitalized using Magpi Data Collection Software [16]. Health facilities were visited to collect information on facility statistics for the year 2013, facility infrastructure, available services, equipment and supplies. The survey was conducted while facilities were awaiting their new batch of quarterly supplies. If supplies were told to be present but not able to be located or accessible during our visit, they were documented as absent. Non-functioning equipment was also recorded as not available.

For the EmONC assessment, the handbook 'Monitoring Emergency Obstetric Care' was used [10]. EmONC signal functions are the key medical interventions that are used to treat direct obstetric complications that cause the vast majority of maternal deaths around the globe. The seven functions of Basic EmONC are expected to be provided at health centre and dispensary level [3]. In referral district hospitals the nine functions of Comprehensive EmONC should be provided to save lives (see Table 1). For assessment of signal functions at dispensary level, focus was on availability of materials and supplies, rather than on performance in the last three months. Therefore signal function 4, manual removal of the placenta, was not included at dispensary level.

\section{Data collection team}

The data collection team consisted of members and volunteers of the WCCP, in collaboration with their partners. For the facility survey, a volunteer nurse-midwife from Australia performed facility visits together with ASM. The EmONC assessment was performed by coauthors JvR and JS, experts of the Working Party on International Safe Motherhood and Reproductive Health 
Table 1 Signal functions for basic and comprehensive EmONC services

\begin{tabular}{ll}
\hline Basic EmONC services & $\begin{array}{l}\text { Comprehensive EmONC } \\
\text { services }\end{array}$ \\
\hline 1) Administer parenteral antibiotics & $\begin{array}{l}\text { Perform signal functions } \\
1-7, \text { plus }\end{array}$ \\
$\begin{array}{ll}\text { 2) Administer uterotonic drugs } & \begin{array}{c}\text { 8erform surgery (cesarean } \\
\text { section) }\end{array} \\
\text { 3) Administer parenteral } & \text { 9) Perform blood transfusion } \\
\text { anticonvulsants } & \\
\text { 4) Manually remove the placenta } & \\
\text { 5) Remove retained products } & \\
\text { 6) Perform assisted vaginal delivery } & \\
\text { 7) Perform basic neonatal } & \\
\text { resuscitation } & \end{array}$
\end{tabular}

in the Netherlands, both consultant obstetricians with several years of working experience in Tanzania and other sub-Sahara African countries. Facilities were notified of the visit prior to arrival. For all facility visits representatives of the District Medical Officer accompanied the team and joined in the assessment. Interviews during the facility survey were conducted with the help of a translator, for the EmONC assessments interviews were done in Kiswahili, with occasional translation.

\section{Data analysis}

All data was entered in Microsoft Excel Version 15.0 to allow for calculation of frequency. To analyse the indicators, data collected from both the EmONC assessment and the facility survey at lower level facilities were used. Birth data was collected from registers (delivery register, admission register, operating theatre register, monthly reports) of the year 2013. If data was not accessible for the whole year, data was extrapolated from known parts of the year. To estimate the expected number of births in the district a Crude Birth Rate of 39 was used based on figures of the Demographic and Health Survey 2010, for mainland rural areas [17]. Research notes based on field visits were compared and discussed within the research team. A report of the facility survey was presented to the District Medical Officer and discussed with a Steering Committee on June $18^{\text {th }}, 2014$. The steering committee is overseeing project activities of the WCCP and comes together on a quarterly basis. Members included district and community representatives. After the EmONC assessment results were presented and discussed at a meeting of the CHMT during their annual planning meeting on December $6^{\text {th }}, 2014$.

\section{Results}

A total of 13 dispensaries, four health centres and one district hospital were included in the facility survey. In 2013, 2504 (21\%) births took place in the district hospital and 2531 (22\%) births in the four health centres. In dispensaries births ranged from 50 to 296 births per year, with a mean of 100 births. Assuming similar patterns in the facilities, which were not surveyed, births in dispensaries were estimated to cover a total of 2600 (22\%) births. In total these facilities covered 7635 facility births, approximately $65 \%$ of the expected births.

None of the dispensaries complied with the guidelines to provide basic EmONC and were either not able to administer one or all of the essential drugs: anti-convulsants, uterotonics or antibiotics. None of the dispensaries had complete birth kits. Five facilities were able to locate all essential neonatal resuscitation equipment. An overview of availability of essential equipment and supplies is presented in Table 2.

Results with regards to the EmONC indicators are presented in Table 3. Three health centres did provide all signal functions for basic EmONC except administration of $\mathrm{MgSO} 4$ to prevent or treat eclampsia (supply problems) and performing assisted vaginal deliveries. One health centre appeared to have more problems; no manual vacuum aspirations were performed, parenteral antibiotics were not administered and newborn resuscitation was not performed. The district hospital was able to provide comprehensive EmONC but did not fully qualify due to non-availability of blood transfusions and no use of the available vacuum extractor in the past three months. Lack of blood was a contributing factor in at least three out of 22 maternal deaths and a frequent indication for referral to the regional hospital in Mwanza. Although a vacuum extractor was available and functioning, observations during the facility visit and lack of documentation on performance of vacuum extraction indicated it unlikely to be used.

\section{Discussion}

None of the facilities in Magu district was able to perform at the expected EmONC-level covering all signal functions. These findings are not surprising considering that the nation wide availability of basic and comprehensive EmONC facilities reduced between 2012 and 2015 [3, 18]. All facilities scored particularly poor on performance of assisted vaginal delivery. Poor clarity on who is qualified, lack of exposure and training and beliefs that higher cadres of health workers should perform such procedures contribute to almost district wide absence of performance of this signal function $[1,19]$. Unavailability of facilities offering full basic and/or comprehensive EmONC is worrisome and contributes to poor outcomes, even after women have reached institutions. Previous studies in Tanzania reached similar conclusions [4, 19-22]. Negative in-facility experiences influence women's perceptions of care and might influence future care seeking, leading to 
Table 2 Facility survey: availability of supplies ${ }^{\mathrm{a}}$ for EmOC in 2014

\begin{tabular}{|c|c|c|c|c|}
\hline \multicolumn{2}{|l|}{ Audit items } & \multirow{2}{*}{$\begin{array}{l}\text { District hospital }(N=1) \\
\text { Yes }\end{array}$} & \multirow{2}{*}{$\begin{array}{l}\text { Health centre }(N=1) \\
\text { Yes }\end{array}$} & \multirow{2}{*}{$\begin{array}{l}\text { Dispensaries }(N=13 \\
10 / 13\end{array}$} \\
\hline Basic equipment & Stethoscope & & & \\
\hline & BP machine & Yes & Yes & $8 / 13$ \\
\hline & Fetoscope & Yes & Yes & $13 / 13$ \\
\hline & Thermometer & Yes & Yes & $9 / 13$ \\
\hline & Urine dipstick & Yes & No & $1 / 13$ \\
\hline & Antiseptic & Yes & Yes & $8 / 13$ \\
\hline & Sterile gauze & Yes & No & $3 / 13$ \\
\hline & Syringes & Yes & Yes & $13 / 13$ \\
\hline & Suture material & Yes & Yes & $12 / 13$ \\
\hline & IV solutions & Yes & Yes & $10 / 13$ \\
\hline & IV giving set & Yes & No & $10 / 13$ \\
\hline & Urine catheters & Yes & No & $2 / 13$ \\
\hline \multirow[t]{6}{*}{ Infection prevention } & Clean/Utility gloves & Yes & Yes & $9 / 13$ \\
\hline & Sterile gloves & Yes & Yes & $12 / 13$ \\
\hline & Chlorine & Yes & Yes & $8 / 13$ \\
\hline & Buckets & Yes & Yes & $9 / 13$ \\
\hline & Ability to boil water & Yes & Yes & $11 / 13$ \\
\hline & Sharp containers & Yes & Yes & $12 / 13$ \\
\hline \multirow[t]{12}{*}{ Childbirth equipment } & Scissors & Yes & Yes & $11 / 13$ \\
\hline & Clamps & Yes & Yes & $10 / 13$ \\
\hline & Cord ties & Yes & No & $8 / 13$ \\
\hline & Ring forceps & Yes & Yes & $5 / 13$ \\
\hline & Needle holder & Yes & Yes & $6 / 13$ \\
\hline & Container for placenta & Yes & Yes & $4 / 13$ \\
\hline & Macintosh & Yes & Yes & $10 / 13$ \\
\hline & Protective wear & Yes & Yes & $7 / 13$ \\
\hline & Vacuum extractor & Yes & No & $0 / 13$ \\
\hline & Self inflating resuscitation bag & Yes & No & $10 / 13$ \\
\hline & Neonatal mask & No & No & $7 / 13$ \\
\hline & Suction equipment & Yes & No & $6 / 13$ \\
\hline MVA & MVA Set & Yes & Yes & $3 / 13$ \\
\hline \multirow[t]{9}{*}{ Medication } & Local anaesthetics & Yes & Yes & $10 / 13$ \\
\hline & Oxytocin/ergometrin & Yes & Yes & $11 / 13$ \\
\hline & Magnesium sulphate/Diazepam & Yes & No & $6 / 13$ \\
\hline & Ampiciline & Yes & Yes & $1 / 13$ \\
\hline & Erythromycin & Yes & No & $6 / 13$ \\
\hline & Gentamycin & Yes & No & $5 / 13$ \\
\hline & Paracetamol & Yes & No & $4 / 13$ \\
\hline & Misoprostol & Yes & Yes & $1 / 13$ \\
\hline & Nevarapine & Yes & Yes & $9 / 13$ \\
\hline \multirow[t]{5}{*}{ Blood tests } & $\mathrm{Hb}$ & Yes & Yes & $0 / 13$ \\
\hline & RPR & Yes & Yes & $0 / 13$ \\
\hline & Malaria & Yes & Yes & $4 / 13$ \\
\hline & HIV & Yes & Yes & $2 / 13$ \\
\hline & Blood grouping & Yes & No & $0 / 13$ \\
\hline
\end{tabular}




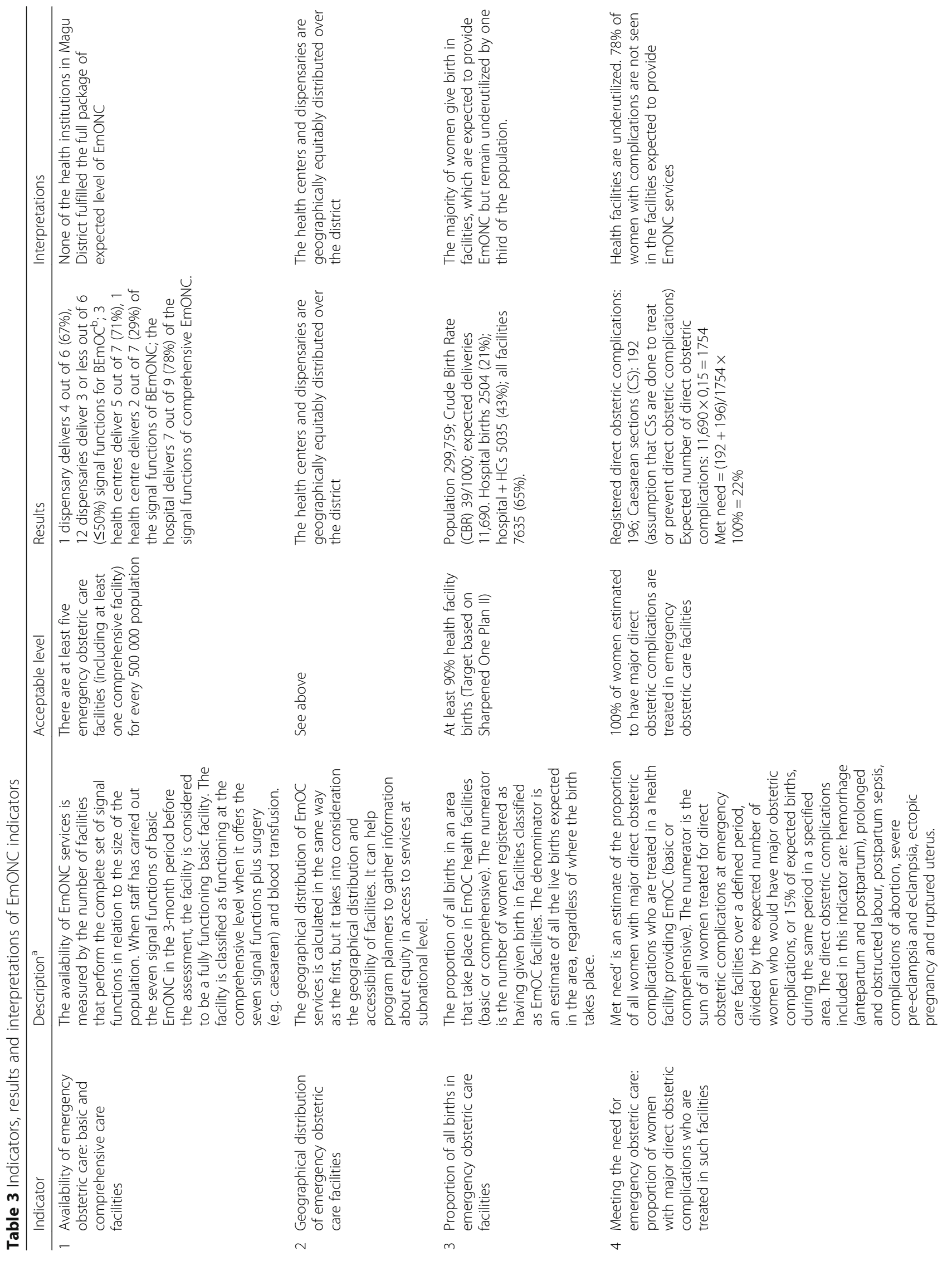




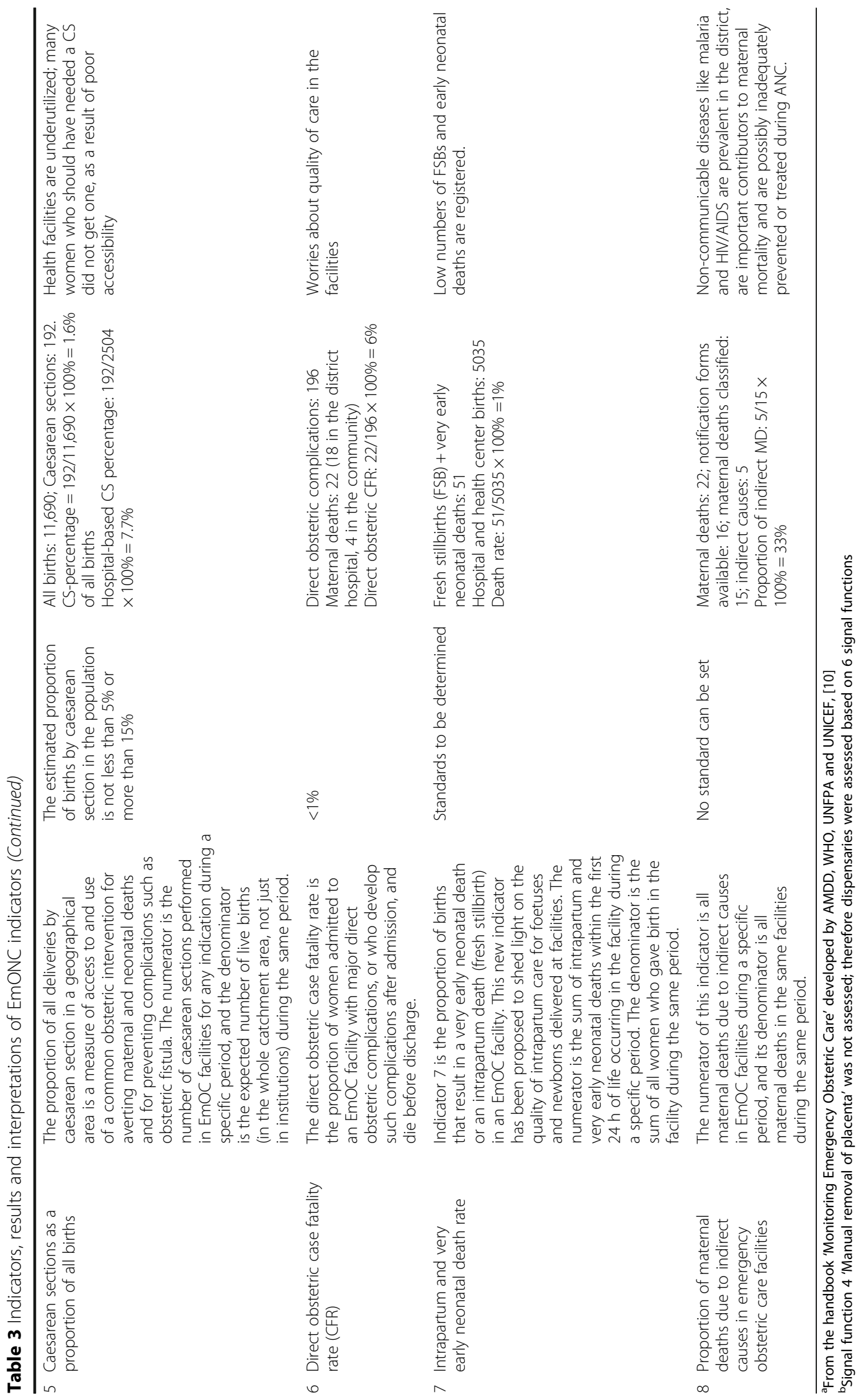


an increase in delay to seek care and preference for home birth [6].

The average facility distribution of 31 facilities per 300.000 population shows there is adequate coverage and plotting the institutions on a map shows good geographical distribution of facilities. Our estimation that $65 \%$ of births took place in health facilities is encouraging, considering the national average of skilled birth attendance of 50\% [17]. However, health facilities appear underutilized as only $22 \%$ of women with expected major obstetric complications were treated in facilities and $1.6 \%$ of births were caesarean sections, similar to findings in other sub-Saharan countries [23].

Although our assessment did not include the full range of Essential Newborn Care it is important to include the ' $\mathrm{N}$ ' in EmONC when conducting such assessments. Newborns have been left out of the global agenda for decades but are now increasingly being acknowledged through initiatives such as the 'Every Newborn Action Plan' [24]. Since fresh stillbirth and early neonatal death are usually caused by complications during childbirth [25], the ' $\mathrm{N}$ ' is a vital part of EmONC assessments. Our assessment found low numbers of fresh stillbirths and early neonatal deaths assuming severe underreporting. To our surprise we did not find any documentation of neonatal deaths outside the district hospital. Monthly reporting books do not request this information, other than number of stillbirths and number of children born with Apgar score below 7 after 5 min. Difficulties in distinguishing between fresh stillbirths versus early neonatal deaths and overall poor reporting of perinatal deaths were challenges found in other studies as well [26].

Maternal deaths have been relatively stable in the district over the past years ranging from 17 to 22 registered maternal deaths [27]. Of the registered deaths in 2013, $81 \%$ occurred in the district hospital. Review of notification forms raised concerns about the quality of care [28]. Of all maternal deaths, 33\% were classified due to indirect causes and could have been prevented with adequate attendance and quality of antenatal care. These findings highlight the importance of ensuring quality of service delivery across the continuum of care.

Although the EmONC indicators are widely used to assess and monitor EmONC performance, their usefulness to understand and improve the level of performance is debated $[4,26]$. Additional assessment methods, beyond reliance on routinely available data, are suggested to be necessary to get a complete picture of the challenges in providing EmONC [23]. Our study shows that assessing supply levels of facilities at a given moment in time can help in gaining a sense of their ability to perform at least 6 of the 7 signal functions. This is in particular useful for facilities with low level of activity (e.g dispensaries) where assessing performance of signal functions over the past three months would not give a realistic idea of their ability to tackle emergencies due to low numbers of births.

Also for the higher-level facilities, inadequate availability of essential medicines and supplies for EmONC affects their ability to perform all signal functions and is a common problem in Tanzania $[4,29,30]$. It is important to note that this does not mean facilities and their staff are not capable or skilled to provide EmONC services. On the contrary, highly skilled health workers can be demoralized due to continuous shortages affecting work motivation and consequently quality of care [31, 32]. Assessments of EmONC should therefore increase attention to supply chain problems, including available procurement and distribution systems and accountability mechanisms.

The assessment captured other weaknesses in the system contributing to poor availability, accessibility and quality of EmONC, which are not captured in the assessment of indicators alone. Poor utilization of the partograph to monitor birth process is a contributor to poor quality of monitoring labour progress and poor outcomes. Although monitoring and management of labour using partograph is part of the signal functions for routine care [9] we argue its use is significant for quality basic EmONC and should therefore not be left aside in EmONC assessments. Insufficient training and limited health worker knowledge contribute to poor use of the partograph [33], however health facility staff reported that unavailability of stationary or funds to print partograph was a major contributing factor for their lack of use.

Similarly, availability of an ambulance for emergency transport depends on families contributing for fuel and cesarean sections could not always be performed at the district hospital due to lack of functioning generator or lack of available anesthesia equipment or blood for transfusion. Such poor organization of services and human resources indicate weaknesses in the system which show how relatively small problems, such as lack of access to stationaries, can prevent access to life saving services [34]. Preventing maternal and perinatal mortality requires a functioning health system, including adequate quality of care in its EmONC facilities. EmONC assessments should therefore be supplemented by mixed methods designs, including qualitative studies, which allow for contextual understanding of findings $[26,35]$.

\section{Limitations}

Our findings should be interpreted with caution. Data collection in dispensaries was restricted to half of the available dispensaries and do, therefore, not necessarily give a complete picture of the district. However, our findings showing inadequate provision of basic EmONC 
services at all levels, make it very unlikely other lower level facilities are fully functioning EmONC facilities. Facility assessment in dispensaries was done prior to receiving new supplies, which should be taken into account. However re-assessment one year later after new supplies were provided did not show much improvement

Although our findings are typical for (maternal) health systems in poor rural districts in sub-Sahara Africa, our assessment was restricted to institutions in Magu District and the findings cannot be extrapolated to other districts. Neighbouring, Busega district, has no District Hospital and therefore women often rely on services of Magu District Hospital. This may have influenced the data explaining the relatively high percentage of facility births. Recall bias could have influenced data quality negatively, since we asked incharges of health centres and district hospital about functioning of their facility in the past three months.

Data quality was limited at all levels of care. The research team observed many problems with documentation and reporting. All delivery books had missing information regarding outcome of birth and whether mother and child went home alive. Also many irregularities and inconsistencies were found between registries within facilities. At dispensary level there were no records of referral or adverse outcomes, despite staff informing us that these do occur. Poor documenting and reporting has been observed in other settings, and despite our knowledge of poor data quality, much of the decision-making is based on these poor numbers [36]. It is easy to assume there is underreporting of complications and poor outcomes, but at the same time many instances where staff do provide high quality of care also go undocumented.

\section{Conclusions}

Although availability of health facilities expected to deliver EmONC are adequate in Magu District, none of the facilities perform all signal functions of BEmONC or CEmONC. Performance of signal functions is dependent on sufficient availability of supplies and resources as well as adequately trained and qualified staff, which can be assessed in line with EmONC indicators. In addition robust data collection systems are required for reliable assessments. Improving assessment approaches to account for local realities and contextual constraints will help to strive for improvements over time. Based on the reported results recommendations were formulated and discussed together with the Council Health Management Team. Importance of implementation of the recommendations and follow up according to the quality cycle was emphasized.

\section{Additional file}

Additional file 1: Questionnaire Facility Audit 2015. (DOCX 550 kb)

\section{Abbreviations}

CHMT: Council Health Management Team; EMONC: Emergency Obstetrics and Neonatal Care; JHPIEGO: Johns Hopkins Program for International Education in Gynaecology and Obstetrics; RMNCH: Reproductive Maternal Neonatal and Child Health; WCCP: Woman Centered Care Project

\section{Acknowledgements}

We thank the District Medical Officer Dr Pembe, the District Nursing Officer Mr. Egdius Mtajwaha, the Hospital Matron Mrs. Joyce Sabora, the doctors in charge of the four health centres (Kabila, Nyanguge, Kahangara, Kisesa) and Naomi Maselle from the Woman Centered Care Project, for their cooperation and their kind assistance. The research team has appreciated the openness, helpfulness and trust of the DMO and his team to allow the research team to conduct this assessment.

\section{Funding}

During the time of writing of this manuscript ASM was supported by the Research Council of Norway through the Global Health and Vaccination Programme (GLOBVAC) for her PhD, project number 244674. The funding body had no role in the design of the study and collection, analysis, and interpretation of data, nor in writing of the manuscript.

\section{Availability of data and materials}

The datasets used and analysed during the current study are available from the corresponding author on reasonable request. Questionnaire used for the facility audit is provided as supplementary material [See Additional file 1]. For data collection and calculation of EmOC indicators we refer to the forms provided in the appendix of the WHO handbook for Monitoring Emergency Obstetric Care [10].

\section{Authors' contributions}

The study was designed by ASM, JVR and JS. Data for the facility audit was collected by all authors. ASM, JVR and JS analysed and interpreted the data with assistance from TB and RK. ASM drafted the manuscript. All authors read and approved the final manuscript.

\section{Competing interests}

The authors declare that they have no competing interests.

\section{Consent for publication}

Not applicable

Ethics approval and consent to participate

Ethical approval for this study was obtained from the National Institute for Medical Research (MR/53/100/103) in Tanzania and VU University Amsterdam in the Netherlands (2013/135). Research clearance for foreign researchers was acquired from the Tanzania Commission For Science and Technology. All facilities and clinical officers or nurses in charge were asked for verbal consent to participate and the District Medical Officer provided written permission to visit the health facilities. Names of those interviewed were documented, however, it was communicated clearly this would not have individual consequences and would not end up in the final reporting.

\section{Publisher's Note}

Springer Nature remains neutral with regard to jurisdictional claims in published maps and institutional affiliations.

\section{Author details}

${ }^{1}$ Institute of Health and Society, Department of Community Medicine and Global Health, Faculty of Medicine, University of Oslo, Oslo, Norway. ${ }^{2}$ Women Centered Care Project, a project of the African Woman Foundation, Magu, Mwanza Region, Tanzania. ${ }^{3}$ Department of Obstetrics and Gynaecology, Sekotoure Regional Referral Hospital, Mwanza, Mwanza Region, Tanzania. ${ }^{4}$ Magu District Council, Magu, Mwanza Region, Tanzania. ${ }^{5}$ Department of Obstetrics, Leiden University Medical Center, Leiden, The Netherlands. 
${ }^{6}$ Athena Institute, VU University, Amsterdam, The Netherlands. ${ }^{7}$ Department of Obstetrics and Gynaecology, Leeuwarden Medical Centre, Henri Dunantweg 2, 8934 AD Leeuwarden, The Netherlands. ${ }^{8}$ Department of Health Sciences, Community and Occupational Medicine, Global Health, University Medical Centre Groningen/University of Groningen, Antonius Deusinglaan 1, P.O. Box 1969700 AD Groningen, The Netherlands.

Received: 9 October 2016 Accepted: 17 March 2017

\section{Published online: 20 March 2017}

\section{References}

1. Ameh C, Msuya S, Hofman J, Raven J, Mathai M, van den Broek N. Status of emergency obstetric care in six developing countries five years before the MDG targets for maternal and newborn health. PLoS One. 2012;7(12):e49938.

2. Afnan-Holmes $\mathrm{H}$, Magoma M, John T, Levira F, Msemo G, Armstrong CE, Martínez-Álvarez M, Kerber K, Kihinga C, Makuwani A, et al. Tanzania's countdown to 2015: an analysis of two decades of progress and gaps for reproductive, maternal, newborn, and child health, to inform priorities for post-2015. Lancet Glob Health. 2015;3(7):e396-409.

3. Ministry of Health and Social Welfare (MoHSW) Reproductive and Child Health Section. The national road map strategic plan to accelerate reduction of maternal, newborn and child deaths in Tanzania, 2008-2015. Dar es Salaam: Ministry of Health $(\mathrm{MoH}) ; 2008$.

4. Olsen OE, Ndeki S, Norheim OF. Availability, distribution and use of emergency obstetric care in northern Tanzania. Health Policy Plan. 2005; 20(3):167-75.

5. Nyamtema AS, Urassa DP, van Roosmalen J. Maternal health interventions in resource limited countries: a systematic review of packages, impacts and factors for change. BMC Pregnancy Childbirth. 2011;11:30.

6. Thaddeus S, Maine D. Too far to walk: maternal mortality in context. Soc Sci Med. 1994;38(8):1091-110.

7. The Partnership for Maternal, Newborn \& Child Health. A global review of the key interventions related to reproductive maternal and child health (RMNCH). Geneva: PMNCH; 2011.

8. Campbell OMR, Graham WJ. Strategies for reducing maternal mortality: getting on with what works. Lancet. 2006;368(9543):1284-99.

9. Gabrysch S, Civitelli G, Edmond KM, Mathai M, Ali M, Bhutta ZA, Campbell OM. New signal functions to measure the ability of health facilities to provide routine and emergency newborn care. PLoS Med. 2012;9(11):e1001340.

10. WHO, UNFPA, AMDD, UNICEF. Monitoring Emergency Obstetric Care: a handbook. Geneva: WHO; 2009.

11. National Bureau of Statistics. 2012 Population and Housing Census. Dar es Salaam: NBS; 2013

12. Solnes Miltenburg A, Rijkers E, Maselle N, van Roosmalen J, Bunders J. Reflections on the dynamics of the coexistence of multiple knowledge cultures in a community-based maternal health project in Tanzania. Knowl Manag Dev J. 2013;9(2):162-84.

13. Vermeulen E, Solnes Miltenburg A, Barras J, Maselle N, van Elteren M, van Roosmalen J. Opportunities for male involvement during pregnancy in Magu district, rural Tanzania. BMC Pregnancy Childbirth. 2016;16:66.

14. Solnes Miltenburg A, Lambermon F, Hamelink C, Meguid T. Maternity care and Human Rights: what do women think? BMC Int Health Hum Rights. 2016;16(1):17.

15. JHPIEGO. Monitoring Birth Preparedness and complication readiness: tools and indicators for maternal and newborn health. Baltimore: JHPIEGO; 2004

16. Magpi. Magpi online data collection tool. 2016. http://home.magpi.com. Accessed Apr-May \& Dec 2014

17. National Bureau of Statistics (NBS) and ICF Macro. Tanzania Demographic and Health Survey 2010. Dar es Salaam: NBS; 2011.

18. MoHCDGEC. The National Road Map Strategic Plan to Improve Reproductive, Maternal, Newborn, Child \& Adolescent Health in Tanzania (2016-2020). One Plan II. Dar es Salaam: Ministry of Health (MoH); 2016.

19. Lobis S, Mbaruku G, Kamwendo F, McAuliffe E, Austin J, de Pinho H. Expected to deliver: alignment of regulation, training, and actual performance of emergency obstetric care providers in Malawi and Tanzania. Int J Gynaecol Obstet. 2011;115(3):322-7.

20. Ueno E, Adegoke AA, Masenga G, Fimbo J, Msuya SE. Skilled birth attendants in Tanzania: a descriptive study of cadres and emergency obstetric care signal functions performed. Matern Child Health J. 2015;19(1):155-69.

21. Hanson C, Ronsmans C, Penfold S, Maokola W, Manzi F, Jaribu J, et al. Health system support for childbirth care in Southern Tanzania: results from a health facility census. BMC Res Notes. 2013;6:435.
22. Sorensen BL, Elsass P, Nielsen BB, Massawe S, Nyakina J, Rasch V. Substandard emergency obstetric care - a confidential enquiry into maternal deaths at a regional hospital in Tanzania. Trop Med Int Health. 2010;15(8):894-900.

23. Campbell OMR, Calvert C, Testa A, Strehlow M, Benova L, Keyes E, et al. The scale, scope, coverage, and capability of childbirth care. Lancet. 2016;6736(16):1-16.

24. UNICEF, WHO. Every newborn: an action plan to end preventable newborn deaths. 2013. www.everynewborn.org.

25. Lawn J, Shibuya K, Stein C. No cry at birth: global estimates of intrapartum stillbirths and intrapartum-related neonatal deaths. Bull World Health Organ. 2005;83:409-17.

26. Banke-Thomas A, Wright K, Sonoiki O, Banke-Thomas O, Ajayi B, llozumba O, et al. Assessing emergency obstetric care provision in low- and middleincome countries: a systematic review of the application of global guidelines. Glob Health Action. 2016;9:31880.

27. Magu District Management Team. Annual Report Magu District Hospital 2013. Magu: DHMT; 2014.

28. Magoma M, Massinde A, Majinge C, Rumanyika R, Kihunrwa A, Gomodoka B. Maternal death reviews at Bugando hospital north-western Tanzania: a 2008-2012 retrospective analysis. BMC Pregnancy Childbirth. 2015;15:333.

29. Mkoka DA, Goicolea I, Kiwara A, Mwangu M, Hurtig A. Availability of drugs and medical supplies for emergency obstetric care: experience of health facility managers in a rural District of Tanzania. BMC Pregnancy Childbirth. 2014;14(1):108.

30. Mselle LT, Moland KM, Mvungi A, Evjen-olsen B, Kohi TW. Why give birth in health facility? Users ' and providers ' accounts of poor quality of birth care in Tanzania. BMC Health Serv Res. 2013;13(1):174.

31. Mkoka DA, Mahiti GR, Kiwara A, Mwangu M, Goicolea I, Hurtig A-K. "Once the government employs you, it forgets you": Health workers' and managers' perspectives on factors influencing working conditions for provision of maternal health care services in a rural district of Tanzania. Hum Resour Health. 2015;13(77):1-13.

32. Penfold S, Shamba D, Hanson C, Jaribu J, Manzi F, Marchant T, et al. Staff experiences of providing maternity services in rural southern Tanzania - a focus on equipment, drug and supply issues. BMC Health Serv Res. 2013;13(1):61.

33. Nyamtema AS, Urassa DP, Massawe $S$, Massawe A, Lindmark G, van Roosmalen J. Partogram use in the Dar es Salaam perinatal care study. Int J Gynaecol Obstet. 2008;100(1):37-40.

34. Jaffré Y. Towards an anthropology of public health priorities: maternal mortality in four obstetric emergency services in West Africa. Soc Anthropol. 2012;20(1):3-18.

35. Spangler SA. Assessing skilled birth attendants and emergency obstetric care in rural Tanzania: the inadequacy of using global standards and indicators to measure local realities. Reprod Health Matters. 2012;20(39):133-41.

36. Graham W, Woodd S, Byass P, Filippi V, Gon G, Virgo S, et al. Diversity and divergence: the dynamic burden of poor maternal health. Lancet. 2016; 6736(16):1-12

\section{Submit your next manuscript to BioMed Central and we will help you at every step:}

- We accept pre-submission inquiries

- Our selector tool helps you to find the most relevant journal

- We provide round the clock customer support

- Convenient online submission

- Thorough peer review

- Inclusion in PubMed and all major indexing services

- Maximum visibility for your research

Submit your manuscript at www.biomedcentral.com/submit
C) Biomed Central 